\title{
New studies on network frequency responses considering dynamic loads
}

\author{
L. T. M. Trang ${ }^{1}$, H. Nouri ${ }^{2}$ \\ ${ }^{1}$ Department of Instrumentation and Control Engineering, Czech Technical University in Prague, Czech Republic \\ ${ }^{2}$ Power System, Electronics and Control Research Laboratory, University of the West of England, United Kingdom
}

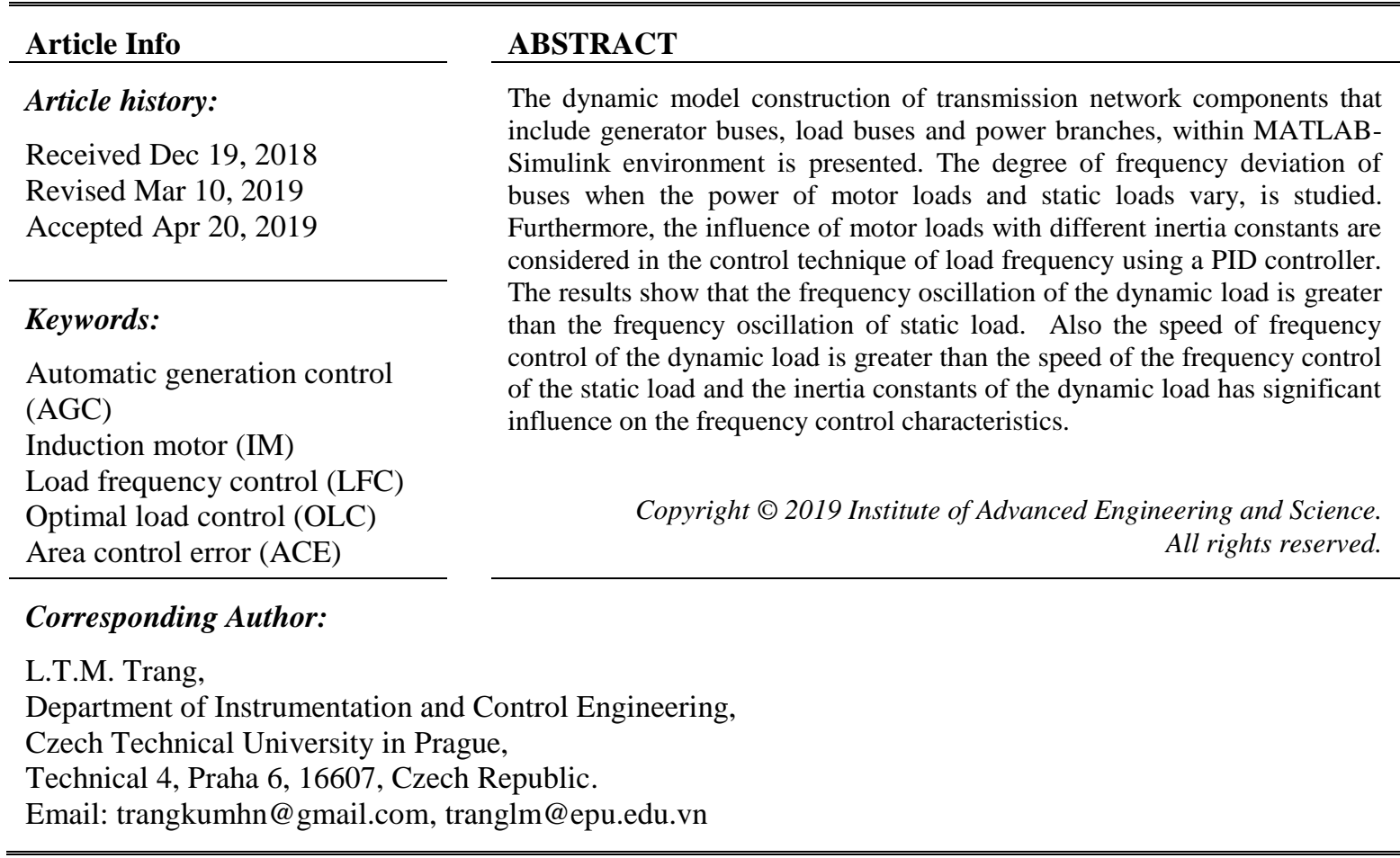

\section{INTRODUCTION}

In recent years, the increasing stress in a transmission system may limit the effective power transfer from generation to the load. At steady state, the frequencies on different buses in a system are synchronized to a common nominal value and the mechanical power is balanced with the electrical power on each bus. Suppose a small change in power balance injection occurs on an arbitrary bus. This mismatch between generation and load causes the bus frequency to deviate from its nominal value. Consequently, the system may lose stability and cause damage to the facilities if the frequency deviations are not tightly controlled around zero. This is important as the frequency of a power system is an indispensable performance signal to the system operator for security and stability considerations. Hence, the desired power system frequency should be kept within a very small, acceptable margin around its nominal value. Otherwise, the system operator must take relevant and effective actions immediately to avoid physical damage to devices.

A power system is a combination of generation, transmission, distribution networks and loads. The active and reactive power demands from different loads vary continuously. The induction motors account for a large portion of electrical loads in industry and air conditioning in business and residential areas. Dynamic characteristics of these loads affect the response of system stability when compared to static loads. Hence, the influence of motors as dynamic loads on transient stability studies have attracted a great deal of attention. The linearized models of dynamic loads [1-3] and load frequency control strategies [4] on a nonlinear system are considered to develop a robust controller.

The real dynamic loads are composed of a variety of motors whose parameters vary over a large range, so the aggregation of motor load with suitable parameters, especially inertia constant $\mathrm{H}$ is very important. This constant significantly influences the transient and dynamic system behavior [5]. In this context, the presence of motor load in a network with influence of inertia constant to frequency response is investigated and reported. 
In an interconnected system, as a power load demand varies randomly, both bus frequency and line power interchange will also vary. The objectives of load frequency control (LFC) are to minimize the transient deviations in these variables (bus frequency and line power interchange) and to ensure their steady state error to be close to zero. Thus, a control system is essential to overcome the effects of the random load changes and to keep the bus frequency within the range of nominal value.

In the past decades, many researchers have investigated the power network frequency regulation. Since the system frequency is essentially related to real power balance, it is natural to control real power output in the generation side through the use of automatic generation control (AGC) system [6-9].

There are some simulation studies of frequency load control in a single area of power network which include one generator or several generators in parallel operation [10-11]. However, for large scale power systems which consist of interconnected control areas, it is important to keep the frequency constant and the tie line power near to its scheduled value. This is achieved by implementing LFC as Tie line controller and PID controller [7-8]. There are much more analytic studies that relate the behavior of the loads and frequency responses of interconnected power network [12-14]. This is normally achieved through establishment of the well-known generation swing equation and implementation of classic tools such as transfer function [12-13] and state space method [15] in the swing equation to estimate the amount of frequency deviation.

With the above motivations, this paper contributes initially to the construction of a dynamic model of a transmission network including generator buses, load buses and power branches within MATLABSimulink environment. Then investigates the degree of frequency deviation of buses when power of motor loads and static loads vary. In addition, the influence of motor loads with different inertia constants are considered in the control technique of load frequency using a PID controller.

The remaining parts of this paper are organized as follows: mathematical modelling of a dynamic system are shown in Section 2; the proposed controller of load frequency and influence of motor load to control quality are presented in Section 3; the simulation results are given in Section 4; and the concluding remarks are given in Section 5.

\section{NETWORK MODEL DEVELOPMENT}

In the interconnected network, buses could possess generators, loads or neither. A generator bus not only has an AC generator that converts mechanical power into electrical power through a rotating prime mover, but some loads may also be attached to it. However, on the load bus, only loads are connected to the load bus.

To construct the dynamic model of a network, the description model of a Turbine-Generation system needs to be developed. Then the models of power equilibrium equation for the generation bus, load bus and power branch between buses need to be established. All of these are essential in the interconnection network for studying dynamics network.

To proceed with these investigations, the following assumptions are considered in this paper: The lines are lossless and characterized by their reactance $\mathrm{X}_{\mathrm{ij}}$. All voltage magnitudes of buses are equal to their nominal values. Reactive power injection on the buses and reactive power flow on the lines are ignored. Rating power of generators is similar in the network model.

\subsection{Mathematical modeling of turbine-generator system}

In terms of AGC under the change of load frequency, the conditions needed to be known are the network model, analysis of load characteristics, linearization of swing dynamics on generator buses, power flow dynamics on the branches, and a measure of dis-utility to users when they participate in frequency control.

In an interconnected power system, AGC equipment is installed for each generator. In steady state, the change of mechanical power $\Delta \mathrm{P}_{\mathrm{Mi}}$ will be a constant. Any change in load is reflected in the frequency.

A study of the system for small changes around a nominal setting, the Turbine-Generator system may be represented by the time constant of turbine $\mathrm{T}_{\mathrm{t}}$ and the time constant of governor TG [9-15].

The generator response is considered to be instantaneous:

$$
\begin{aligned}
& \frac{d \Delta P_{M i}}{d t}=-\frac{1}{T_{t i}} \Delta P_{M i}+\frac{1}{T_{t i}} \Delta x_{g v i} \\
& \frac{d \Delta x_{g v i}}{d t}=-\frac{1}{T_{G i}} \Delta x_{g v}-\frac{1}{T_{G i} R_{i}} \Delta f_{i}+\frac{1}{T_{G i}} \Delta P_{C i}
\end{aligned}
$$

Laplace transformation of (1) and (2) yield: 
$\Delta P_{M i}(s)=\frac{1}{\left(1+s T_{t i}\right)\left(1+s T_{G i}\right)}\left[\Delta P_{C i}(s)-\frac{1}{R_{i}} \Delta F_{i}(s)\right]$

\subsection{Mathematical modeling of power equilibrium equation}

The increment in power input to the generator-load system is defined as $\left(\Delta P_{G i}-\Delta P_{L i}\right)$.

$\Delta P_{G i}=\Delta P_{M i}-\Delta P_{l o s s, G i}$

$\Delta P_{G i}=\Delta P_{M i}-\Delta P_{\text {loss }, G i}$

This increment in power input to the system is accounted for in three ways [14]:

(i) Rate of increase of stored kinetic energy in the generator rotor. At scheduled frequency $\left(\mathrm{f}^{0}\right)$, the stored energy is:

$W_{k e i}^{0}=H_{G i} \times P_{r i}$

The kinetic energy being proportional to square of speed (or frequency), at a frequency of $\left(f^{0}+\Delta f_{i}\right)$ the kinetic energy is given by:

$W_{k e i}=W_{k e i}^{0}\left(\frac{f^{0}+\Delta \mathrm{f}_{i}}{f^{0}}\right)^{2} \approx H_{G i} P_{r i}\left(1+\frac{2 \Delta \mathrm{f}_{i}}{f^{0}}\right)$

Therefore, the rate of change of kinetic energy is:

$\frac{d}{d t}\left(W_{k e i}\right)=\frac{2 H_{G i} P_{r i}}{f^{0}} \frac{d}{d t}\left(\Delta \mathrm{f}_{i}\right)$

(ii) As the frequency changes, the motor load changes, being sensitive to the speed, the rate of change load with respect to frequency:

$D_{L i} \Delta \mathrm{f}_{i}=\frac{\partial P_{D}}{\partial f} \Delta \mathrm{f}_{i}$

where $D_{L i} \Delta \mathrm{f}_{i}$ is the load change that is frequency sensitive. $D_{L i}=\frac{\partial P_{D i}}{\partial f}(\mathrm{MW} / \mathrm{Hz})$ expressed as $\%$ change in load divided by $\%$ change in frequency. $\mathrm{D}_{\mathrm{Li}}$ can be determined empirically.

(iii) Rate of increase export of power lines $\Delta P_{\text {line, } i}$

The power equilibrium equation could be expressed as:

$\Delta P_{G i}-\Delta P_{L i}=\frac{2 H_{G i} P_{r i}}{f^{0}} \frac{d}{d t}\left(\Delta \mathrm{f}_{i}\right)+D_{L i} \Delta \mathrm{f}_{i}+\Delta P_{\text {line }, i}$

Dividing (10) by $\mathrm{P}_{\mathrm{r}}$ and rearranging it in per unit $(\mathrm{pu})$ :

$\Delta P_{G i}(\mathrm{pu})-\Delta P_{L i}(\mathrm{pu})=\frac{2 H_{G i}}{f^{0}} \frac{d}{d t}\left[\Delta \mathrm{f}_{i}(\mathrm{pu})\right]+D_{L i} \Delta \mathrm{f}_{i}(\mathrm{pu})+\Delta P_{\text {line }, i}(p u)$

From (4) and (5) the change in the generator power is derived as $\Delta P_{G i}=\Delta P_{M i}-D_{G i} \Delta \mathrm{f}_{i}$, which could be substituted in (11) to yield (12) and then (13) in pu:

$\frac{2 H_{G i}}{f^{0}} \frac{d}{d t}\left[\Delta \mathrm{f}_{i}(\mathrm{pu})\right]+D_{G i} \Delta \mathrm{f}_{i}(\mathrm{pu})+D_{L i} \Delta \mathrm{f}_{i}(\mathrm{pu})=\Delta P_{M i}(\mathrm{pu})-\Delta P_{\text {line }, i}(\mathrm{pu})-\Delta P_{L i}(\mathrm{pu})$

$\frac{2 H_{G i}}{f^{0}} \Delta \dot{f}(p u)+\left(D_{L i}+D_{G i}\right) \Delta \mathrm{f}(\mathrm{pu})=\Delta P_{M i}(p u)-\Delta P_{\text {line }, i}(\mathrm{pu})-\Delta P_{L i}(\mathrm{pu})$

\subsection{Mathematical modeling of generator bus}

Each generator bus could be represented as Figure 1 [16] where:

$\Delta P_{\text {line }, i}(\mathrm{pu})=\Delta P_{i}^{\text {out }}(\mathrm{pu})-\Delta P_{i}^{\text {in }}(\mathrm{pu})$ 


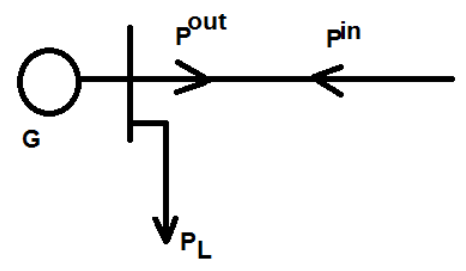

Figure 1. Power diagram of generator bus

The corresponding power equilibrium equation in per unit could be expressed as:

$\frac{2 H_{G i}}{f^{0}} \Delta \dot{f}_{i}(p u)+\left(D_{L i}+D_{G i}\right) \Delta f_{i}(p u)=\Delta P_{M i}(p u)-\Delta P_{i}^{o u t}(\mathrm{pu})+\Delta P_{i}^{i n}(p u)-\Delta P_{L i}(\mathrm{pu})$

Let $\widetilde{D}_{i}=\left(D_{G i}+\mathrm{D}_{\mathrm{Li}}\right) ; K_{p i}=1 / \widetilde{D}_{i}, T_{p i}=\frac{2 H_{G i}}{f^{0} \widetilde{D}_{i}}$

Laplace Transform (LT) of equation (15) yields:

$\Delta F_{i}(s)=\frac{K_{p i}}{\left(1+T_{p i} s\right)}\left[\Delta P_{M i}(s)-\Delta P_{L i}(s)-\Delta P_{i}^{o u t}(s)+\Delta P_{i}^{i n}(s)\right]$

\subsection{Mathematical modeling of load bus}

The load on a power system consists of variety of electrical drives. There are either the dynamic loads (e.g. induction motor) or the static loads A dynamic load model that can expressed as in [10]:

$P_{\text {Loadi }}^{f}-P_{\text {Loadi }}^{f 0}=\Delta P_{\text {Loadi }}^{f}=\mathrm{D}_{\mathrm{Li}} \Delta f_{i}+h\left(\Delta \dot{f}_{l}\right)=0$

Where $\mathrm{D}_{\mathrm{Li}}$ is the damping of load at bus $\mathrm{i}^{\text {th }}$

The rotating masses of Induction Motor (IM) load following kinetic energy:

$W_{k e i}(f)=\frac{1}{2} J_{i} \omega_{i}^{2}$

Where $\mathrm{H}_{\mathrm{i}}=\mathrm{J}_{\mathrm{i}} \omega_{\mathrm{i}}$ with $\mathrm{J}_{\mathrm{i}}$ is moment of inertia

The change in the kinetic energy, which is equal to the power consumed $\mathrm{P}_{\text {IMi }}$ by IM is given by:

$P_{I M i}=\frac{d W_{k e i}(f)}{d t}$

And:

$-\Delta P_{I M i}=\frac{d \Delta W_{k e i}(f)}{d t}=\frac{2 H_{I M i} P_{r i}}{f^{0}} \frac{d}{d t}(\Delta \mathrm{f})$

From (17) and (20), the change of motor power in pu as:

$\Delta P_{\text {Loadi }}^{f}(p u)=D_{L i} \Delta f_{i}+\frac{2 H_{I M i}}{f_{0}} \frac{d \Delta \mathrm{f}_{i}}{d t}$

A load at bus $i^{\text {th }}$ is modeled by the equation in pu:

$\frac{2 H_{I M i}}{f^{0}} \Delta \dot{f}_{i}(\mathrm{pu})+D_{L i} \Delta f_{i}(\mathrm{pu})=-\Delta P_{L i}(\mathrm{pu})-\Delta P_{i}^{o u t}(\mathrm{pu})+\Delta P_{i}^{i n}(\mathrm{pu})$

Let $T_{p i}^{\prime}=\frac{2 H_{i}}{\mathrm{D}_{\mathrm{Li}} f^{0}} ; K^{\prime}{ }_{p i}=\frac{1}{\mathrm{D}_{\mathrm{Li}}}$

Laplace transform (LT) for (22) yields:

$\Delta F_{i}(s)=\frac{\mathrm{K}^{\prime} \mathrm{pi}}{\left(1+T^{\prime} \mathrm{pi}^{\prime} s\right)}\left[-\Delta P_{L i}(s)-\Delta P_{i}^{\text {out }}(s)+\Delta P_{i}^{\text {in }}(s)\right]$ 
A static load model that can expressed as in [17]:

$\Delta P_{\text {Loadi }}^{\text {static }}=\mathrm{D}_{\mathrm{Li}} \Delta f_{i}$

The frequency deviation $\Delta \boldsymbol{f}_{\boldsymbol{i}}$ is calculated similar to induction motor but without change in store kinetic energy.

$D_{L i} \Delta f_{i}(p u)=-\Delta P_{L i}(\mathrm{pu})-\Delta P_{i}^{\text {out }}(\mathrm{pu})+\Delta P_{i}^{\text {in }}(\mathrm{pu})$

\subsection{Mathematical modeling of of branch power} is yielded:

Assume that the line admittance parameters are purely imaginary, branch power connected to bus $i^{\text {th }}$

$P_{i}=\sum_{k=1}^{n}\left|V_{i}\right|\left|V_{k}\right| B_{i k} \sin \left(\theta_{i}-\theta_{k}\right)$

Where: $V_{i}=\left|V_{i}\right| \angle \theta_{i}, V_{k}=\left|V_{k}\right| \angle \theta_{k}$. In this case $\left|V_{i}\right|\left|V_{k}\right| B_{i k}$ are constants.

Linearizing $\mathrm{P}_{\mathrm{i}}$ around the operating point: $P_{i}=P_{i}^{0}+\Delta P_{i}$ and $\theta_{i}=\theta_{i}^{0}+\Delta \theta_{i}, \theta_{k}=\theta_{k}^{0}+\Delta \theta_{k}$

$P_{i}=P_{i}^{0}+\Delta P_{i}=\sum_{k=1}^{n}\left|V_{i}\right|\left|V_{k}\right| B_{i k} \sin \left(\theta_{i}^{0}+\Delta \theta_{i}-\theta_{k}^{0}-\Delta \theta_{k}\right)$
$=\sum_{k=1}^{n}\left|V_{i}\right|\left|V_{k}\right| B_{i k}\left[\sin \left(\theta_{i}^{0}-\theta_{k}^{0}\right) \cos \left(\Delta \theta_{i}-\Delta \theta_{k}\right)+\sin \left(\Delta \theta_{i}-\Delta \theta_{k}\right) \cos \left(\theta_{i}^{0}-\theta_{k}^{0}\right)\right.$

Let assume that the angle of increments tends to zero:

$\cos \left(\Delta \theta_{i}-\Delta \theta_{k}\right) \approx 1 ; \sin \left(\Delta \theta_{i}-\Delta \theta_{k}\right) \approx\left(\Delta \theta_{i}-\Delta \theta_{k}\right)$

$$
\Delta P_{i}=\sum_{k=1}^{n}\left|V_{i}\right|\left|V_{k}\right| B_{i k} \cos \left(\theta_{i}^{0}-\theta_{k}^{0}\right)\left(\Delta \theta_{i}-\Delta \theta_{k}\right)
$$

Let $T^{\prime}{ }_{i k}=\left|V_{i}\right|\left|V_{k}\right| B_{i k} \cos \left(\theta_{i}^{0}-\theta_{k}^{0}\right)$

$\Delta P_{i}=\sum_{k=1}^{n} T^{\prime}{ }_{i k}\left(\Delta \theta_{i}-\Delta \theta_{k}\right)$

Assume coherency between the internal and terminal voltage phase angles of each generator so that these angles tend to "swing" together: $\Delta \theta_{i}=\Delta \delta_{i}$

$\Delta P_{i}(p u)=\sum_{k=1}^{n} T^{\prime}{ }_{i k}\left(\Delta \delta_{i}-\Delta \delta_{k}\right)$
$\Delta P_{i}(p u)=2 \pi \sum_{k=1}^{n} T^{\prime}{ }_{i k}\left(\int \Delta f_{i} d t-\int \Delta f_{k} d t\right)$

Let $T_{i k}=2 \pi T^{\prime}{ }_{i k}$.

Laplace Transform (LT) for equation (29) yields:

$\Delta P_{i}(s)=\frac{1}{s} \sum_{k=1}^{n} T_{i k}\left[\Delta F_{i}(s)-\Delta F_{k}(s)\right]$ 


\subsection{Dynamic network model}

In summary the dynamic model of the transmission network is specified by (15), (22) (25) and (31). To simplify notation, let drop the (pu) from the variables denoting per unit and write (15), (22) (25) and (31) as:

$$
\begin{aligned}
& \frac{2 H_{G i}}{f^{0}} \Delta \dot{f}_{i}+\left(D_{L i}+D_{G i}\right) \Delta f_{i}=\Delta P_{M i}-\Delta P_{i}^{\text {out }}+\Delta P_{i}^{\text {in }}-\Delta P_{L i} \\
& \frac{2 H_{I M i}}{f^{0}} \Delta \dot{f}_{i}+D_{L i} \Delta f_{i}=-\Delta P_{L i}-\Delta P_{i}^{\text {out }}+\Delta P_{i}^{\text {in }} \\
& D_{L i} \Delta f_{i}=-\Delta P_{L i}-\Delta P_{i}^{\text {out }}+\Delta P_{i}^{\text {in }} \\
& \Delta P_{i}=2 \pi \sum_{k=1}^{n} T^{\prime}{ }_{i k}\left(\int \Delta f_{i} d t-\int \Delta f_{k} d t\right)
\end{aligned}
$$

The model (33)-(36) captures the power system behavior at the timescale of seconds.

\section{THE PROPOSED LOAD FREQUENCY CONTROLLER WITH CONSIDERATION OF THE MOTOR LOAD INFLUENCE}

In this paper, consider all loads at buses to be induction motors. They are compared to static loads used in the same network model. These dynamic loads will bring significant impact to the power system in term of frequency due to the kinetic energy that is stored in the rotating masses of the motors [18]. Dynamic load modeling mentioned in previous part is widely used as a model to analyse power system stability problems. The effect of the induction motor on the stability of the system is analyzed by changing inertia constant through small disturbance. A large inertia constant of motor load entails slow frequency dynamics in response to generation-load imbalance.

As there is a step change in load, the turbine-governor takes action that changes the mechanical power injection in response to frequency deviation to rebalance power. It is possible to include any secondary frequency control mechanism such as AGC that operates at a slower timescale to restore the nominal frequency. A proposed two-area control scheme for LFC [17, 19] is applied to control frequency in this paper. The simulated responses of LFC model will be compared in the tie line controller (without PID block) [11] and the proposed PID controller given in Figure 2. This comparison is based on the oscillation and response time of frequency at buses in the network. This indicates the relative stability of the system.

The frequency control model of the two area system but with the additional PID controller is shown in Figure 2. Suppose there is a change in load $\left(\Delta \mathrm{P}_{\mathrm{Li}}\right)$ in any bus in the system, the frequencies at buses in the system settle to a steady state value.

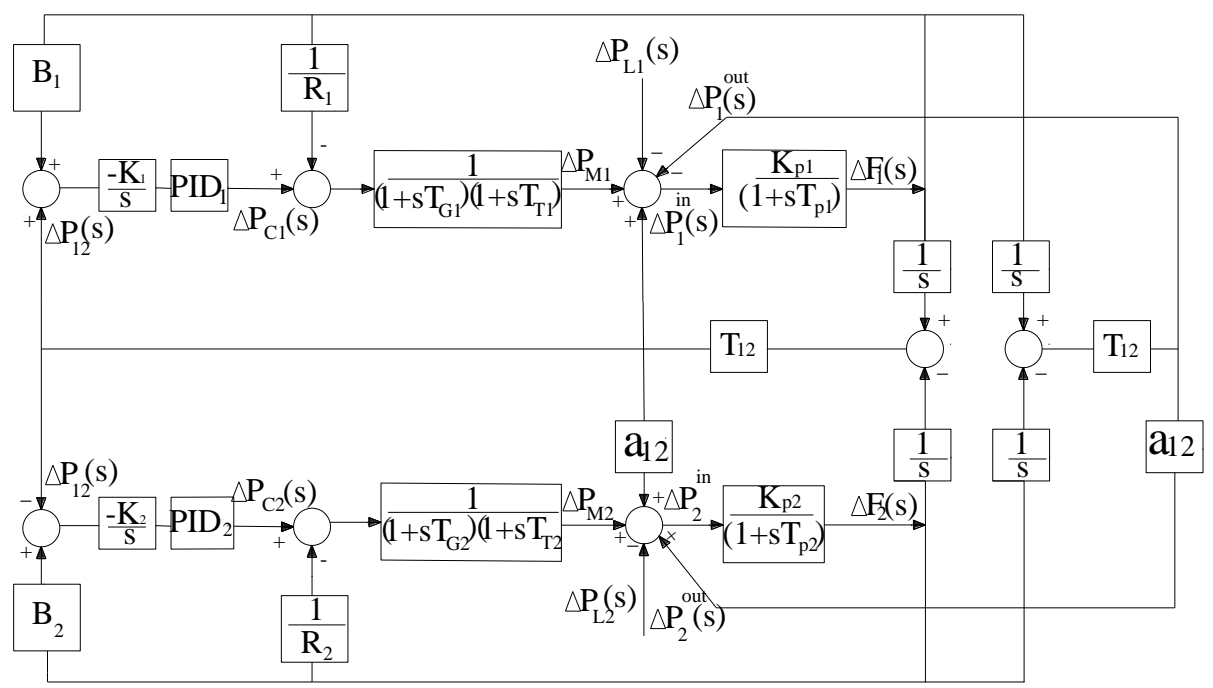

Figure 2. Propose control block diagram of two-area interconnected system 


\section{RESULTS AND DISCUSSIONS}

\subsection{Sub frequency deviation response in dynamic network model}

In this paper, the proposed approach is applied on a $230 \mathrm{kV}$ power system of Figure 3. The system consists of three thermal generating units, the connected branches that have the same impedances, and the loads that are placed on buses 2, 3, 4 and 5. The frequency deviation response is illustrated with a sudden load increase of $10 \%(\Delta \mathrm{P}=0.1$ p.u) on bus 3 at $\mathrm{t}=0.2 \mathrm{~s}$. For the purpose of analysis, performance of the dynamic system model and static model under various scenarios are compared. The system data are given in the Table 1,2,3 and the Induction motors data are $\eta$ (efficiency) $=80 \%$; pf (power factor) $=0.85$ lag; Pout $=$ $50 \mathrm{HP}$; and inertia constant $\mathrm{H}_{\mathrm{IMi}}=6$. It is assumed that static loads connected to the four buses (bus 2, bus 3 , bus 4 and bus 5) have equal power magnitude as induction motors at each respective bus.

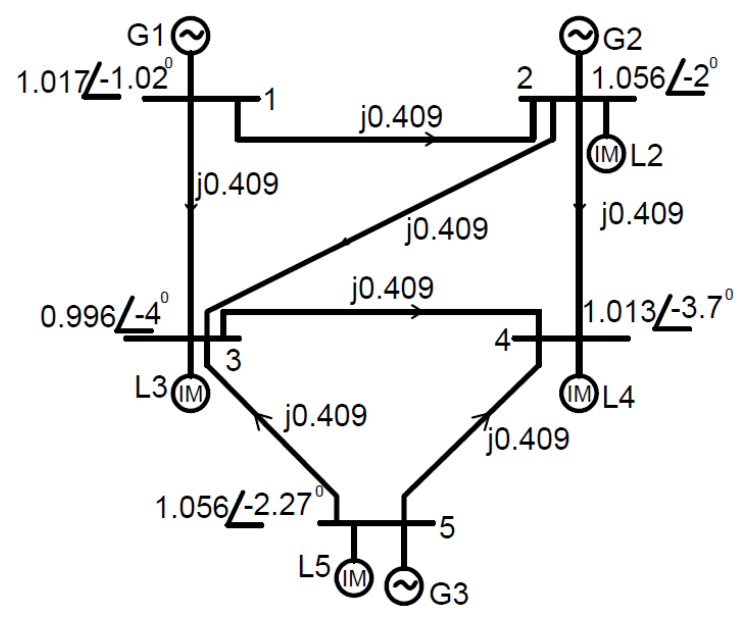

Figure 3. Test system diagram

Table 1. Generator Data

\begin{tabular}{cccccccc}
\hline No.Gen & Type & $\mathrm{H}$ & $\mathrm{R}$ & $\mathrm{X}_{\mathrm{d}}$ & $\mathrm{T}_{\mathrm{G}}$ & $\mathrm{T}_{\mathrm{T}}$ & $\mathrm{D}_{\mathrm{G}}$ \\
\hline 1 & Steam & 9 & 0.03 & 1.3125 & 0.2 & 0.3 & 0.1 \\
2 & Steam & 9 & 0.03 & 1.3125 & 0.2 & 0.3 & 0.1 \\
3 & Steam & 9 & 0.03 & 1.3125 & 0.2 & 0.3 & 0.1 \\
\hline
\end{tabular}

Table 2. PID Controller Data

\begin{tabular}{cccc}
\hline No. PID & $\mathrm{K}_{\mathrm{P}}$ & $\mathrm{K}_{\mathrm{I}}$ & $\mathrm{K}_{\mathrm{D}}$ \\
\hline 1 & 15 & 10 & 7 \\
2 & 20 & 15 & 10 \\
\hline
\end{tabular}

Table 3. Bus Data

\begin{tabular}{ccccc}
\multicolumn{5}{c}{ Table 3. Bus Data } \\
\hline Bus & $\mathrm{V}_{\mathrm{i}} \mid(\mathrm{pu})$ & $\delta_{\mathrm{i}} \mid(\mathrm{pu})$ & $\mathrm{D}_{\mathrm{L}}$ \\
\hline 1 & 1.017 & -1.02 & \\
2 & 1.0566 & -2 & 0.6 \\
3 & 0.996 & -4 & 0.6 \\
4 & 1.013 & -3.7 & 0.6 \\
5 & 1.0566 & -2.2717 & 0.6 \\
\hline
\end{tabular}

The test network is modeled in the MATLAB/Simulink environment. Several scenarios of connections among generator buses, load buses and power branches listed in Table 4 are considered. The loads are modelled as frequency dependent loads. The responses of the frequency deviations at bus 1 (generator 1) are chosen as a reference bus for comparison between motor loads and static loads under various scenarios as shown in Figure 4 to Figure 13. 
Table 4. Cases of Changing Connected Networks

\begin{tabular}{ccccccccccc}
\hline Case & 1 & 2 & 3 & 4 & 5 & 6 & 7 & 8 & 9 & 10 \\
\hline G1 & J & J & J & J & J & J & J & J & J & J \\
G2 & J & J & J & J & J & J & J & J & J & J \\
G3 & & & & & & & J & J & J & J \\
Line 1-2 & J & J & J & J & J & J & J & J & J & J \\
Line 1-3 & J & J & J & J & J & J & J & J & J & J \\
Line 2-4 & & J & J & J & J & J & J & J & J & J \\
Line 2-3 & & & J & J & & J & J & J & & J \\
Line 3-4 & & & J & J & J & J & J & J & J \\
Line 3-5 & & & & & J & & J & J & J \\
Line 4-5 & & & & & & J & & J & J \\
\hline
\end{tabular}

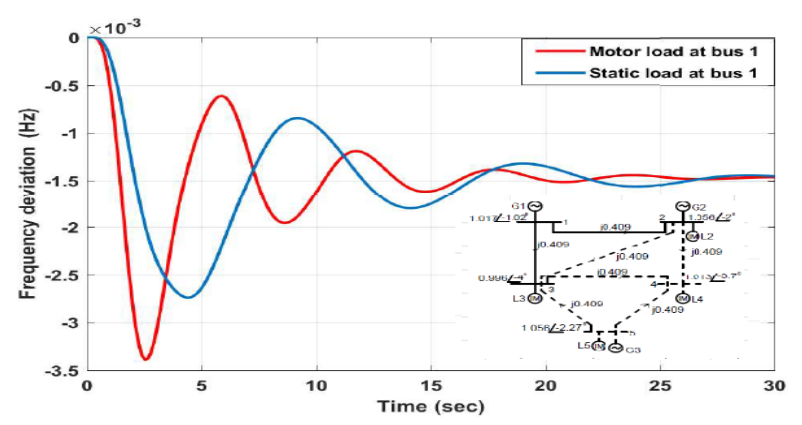

Figure 4. Frequency deviation in case 1

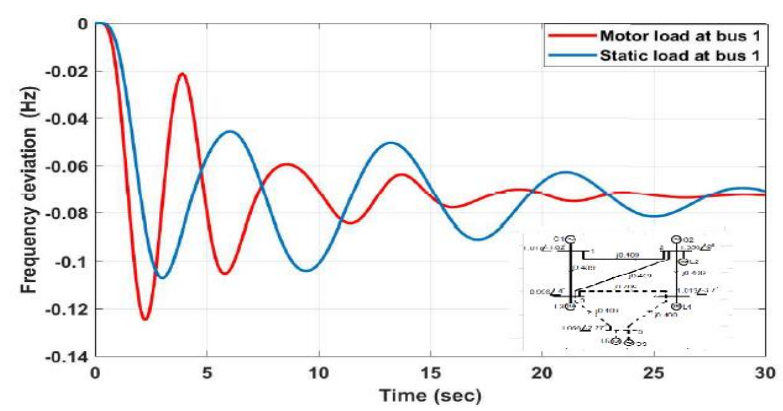

Figure 6. Frequency deviation in case 3

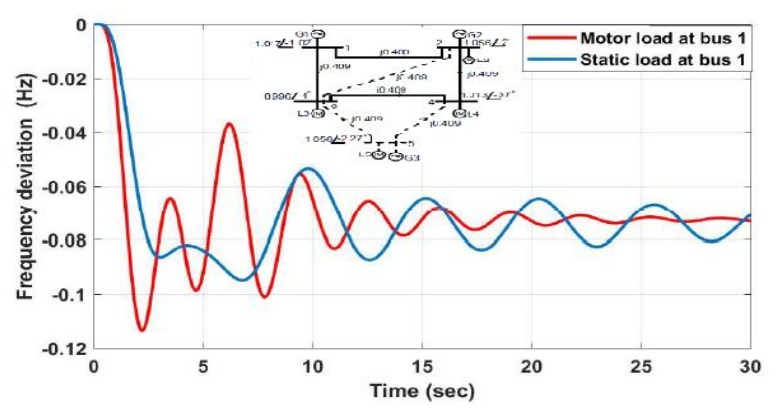

Figure 8. Frequency deviation in case 5

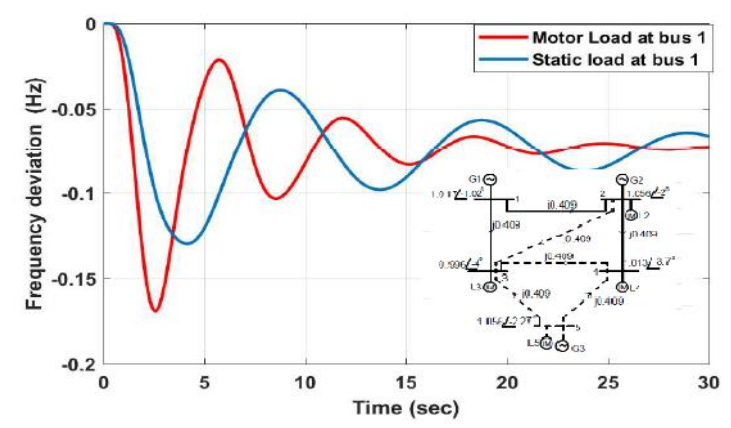

Figure 5. Frequency deviation in case 2

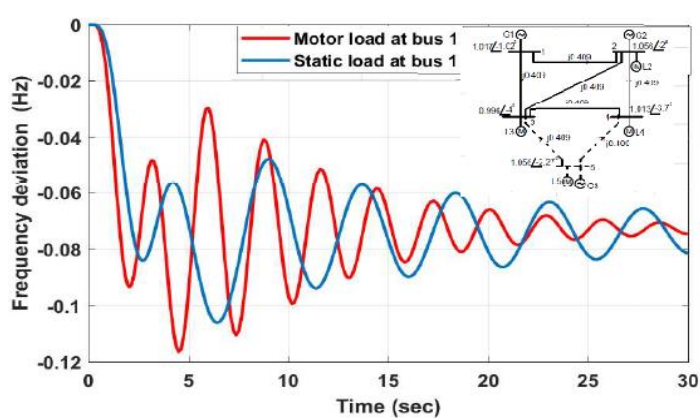

Figure 7. Frequency deviation in case 4

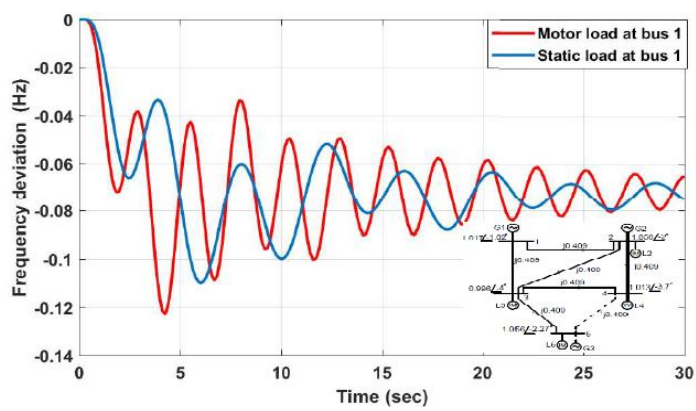

Figure 9. Frequency deviation in case 6 


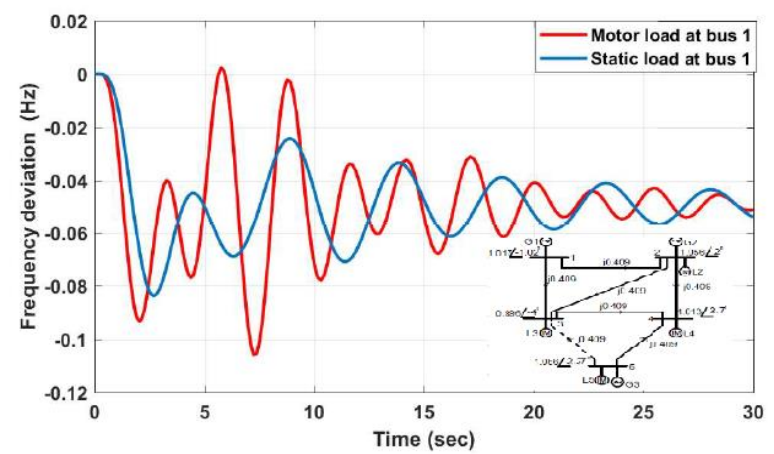

Figure 10. Frequency deviation in case 7

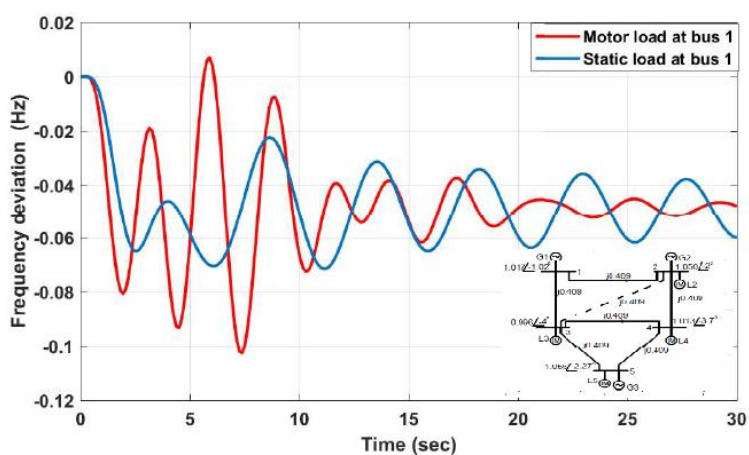

Figure 12. Frequency deviation in case 9

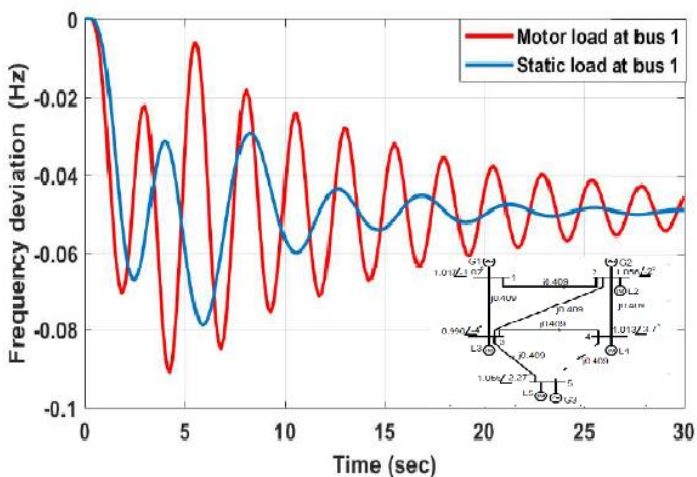

Figure 11. Frequency deviation in case 8

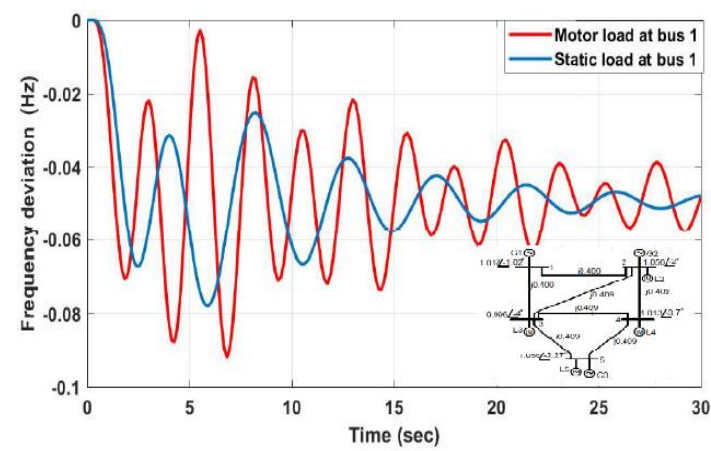

Figure 13. Frequency deviation in case 10

Increasing the load by $10 \%$ at bus 3 , in the case 1 there is small drop in frequency deviation at bus 1 and steady state response time is almost 27 seconds in both static loads and motor loads. However, the frequency deviation at bus 1 increases graduatelly for cases 2 to 10 . When adding line 2-4 to network model in the case 2, there is a significant change of frequency at bus 1 and it takes more than 30 seconds to reach the steady state. In the case 3 , the oscillation of frequency at bus 1 reduces compared to the case 2 due to there are one more line 2-3 connected to network. In addition, the frequency osscillation and time response are higher for cases 4 to 10. These changes are related to addition of more loads and lines at buses in the network. In general, more incremental oscillations of the frequency deviation response observed at buses with motor loads than the static loads.

\subsection{Influence of motor load to the proposed load frequency control response}

The proposed load frequency control system with the addition of a PID controller is implemented at generators G1 and G2 in the full network (case 10) where the total load at bus 3 is increased by $10 \%$. The network parameters and the gains of the PID controller are given in the Appendix. In order to evaluate reliability of the control system, the frequency response of the proposed controller is compared with the conventional Tie line controller for bus 1, bus 2 and bus 5 (generator buses) as shown in Figure14-16 respectively. Based on these results, the PID controller give the frequency responses less oscillation and more precise than Tie line conntroller. Therefore, the load frequency control system with PID controller is continued to implement comparasion freqency responses in the system between motor loads and static loads.

The analysis of Figure 17-19 show that the speed of frequency control response of motor loads is faster than the frequency control response of static loads. This is due to among the motor loads and generators transfer kinertic energy together, they support together and help for frequency responses reaching the steady state quickly. 


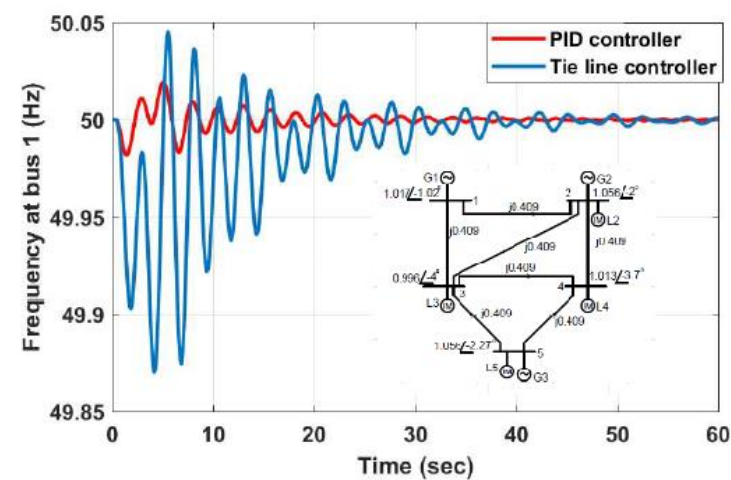

Figure 14. Frequency response at bus 1

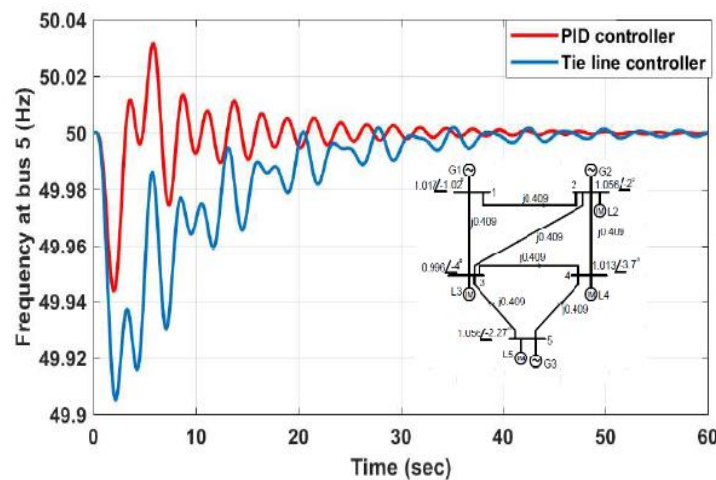

Figure 16. Frequency response at bus 5

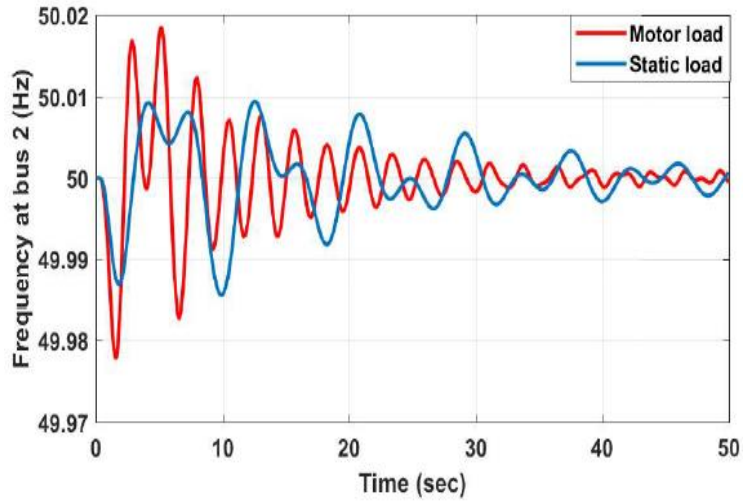

Figure 18. Frequency response at bus 2

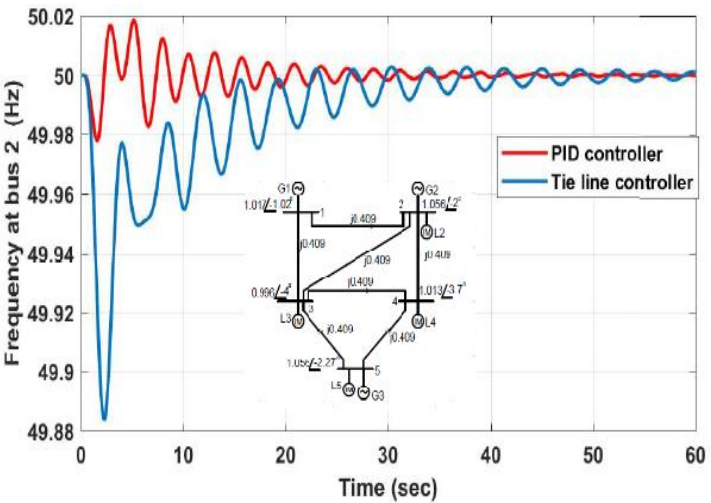

Figure 15. Frequency response at bus 2

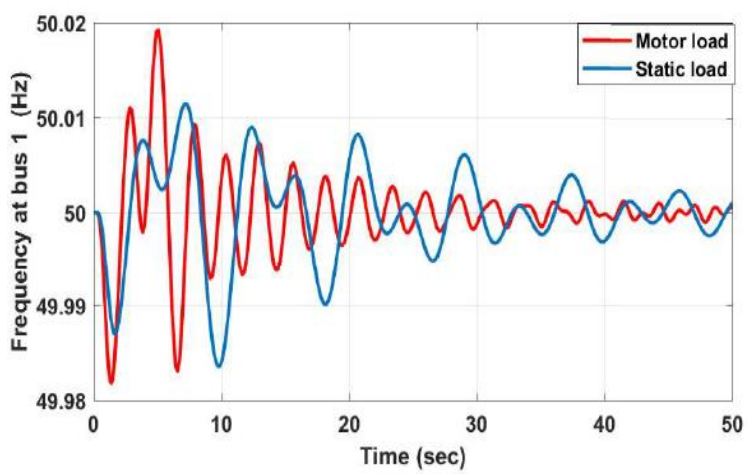

Figure 17. Frequency response at bus 1

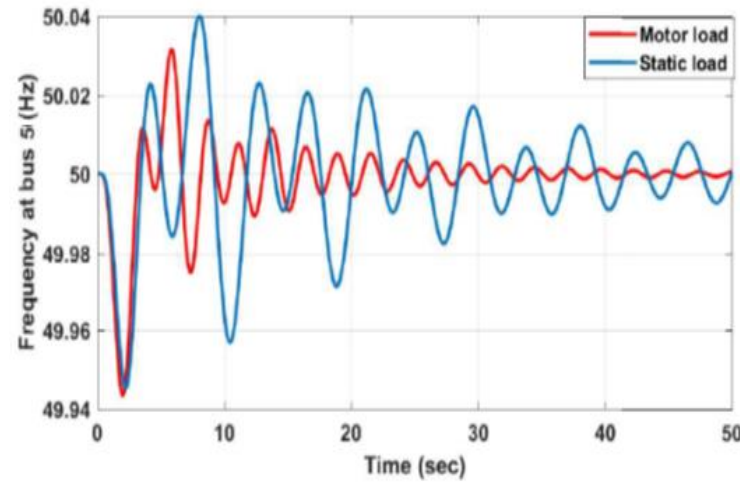

Figure 19. Frequency response at bus 5

Finally, the different load inertia constants $\mathrm{H}_{\mathrm{IMi}}=(5 ; 5.5 ; 6 ; 6.5 ; 7)$ at bus 3 (increase $10 \%$ load) are implemented in the proposed PID control system to gain frequency responses at respective buses in the network. The simulated results are shown in Figure 20-22. The tentative analysis of the obtained results suggest that value of inertia $\mathrm{H}_{\mathrm{IMi}}$ of the motor has a direct effect on the initial slope and the time of the peak response of frequency. However, $\mathrm{H}_{\mathrm{IMi}}$ does not affect the final steady state value of frequency. 


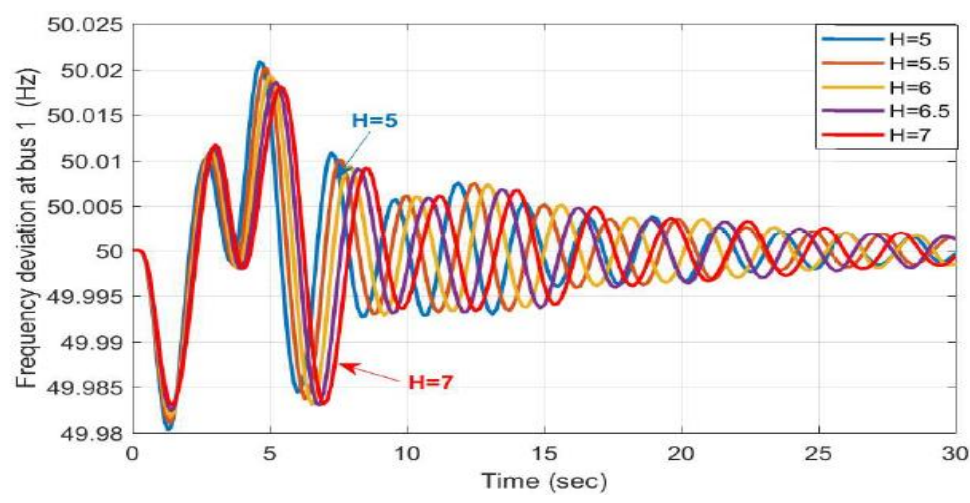

Figure 20. Frequency response in bus 1

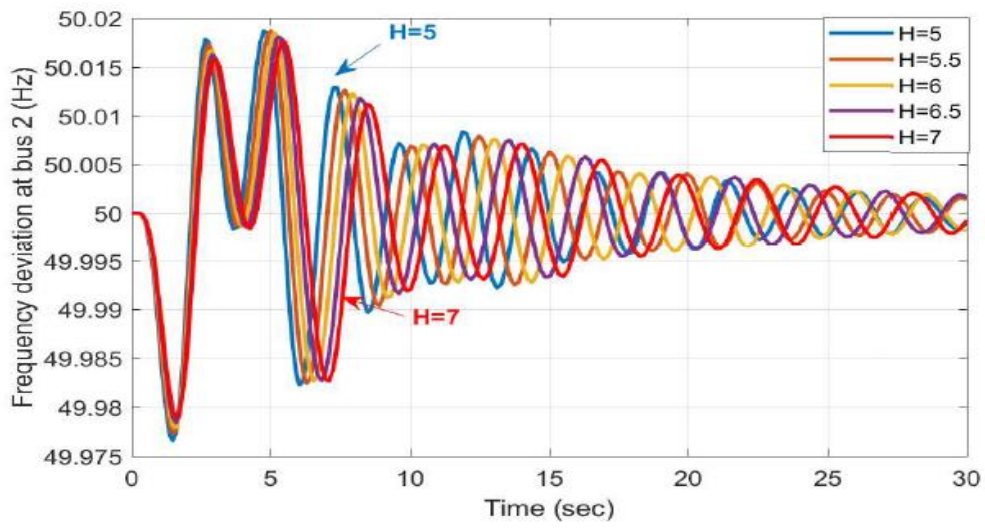

Figure 21. Frequency response in bus 2

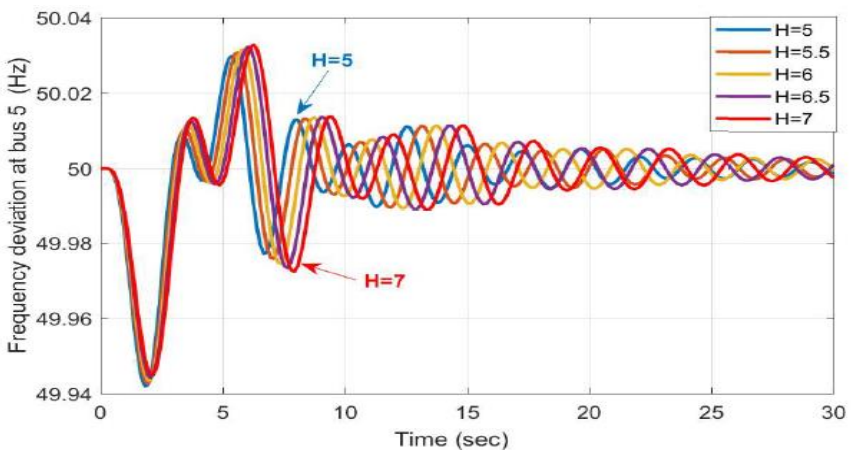

Figure 22. Frequency response in bus 5

\section{CONCLUSION}

The model of a dynamic network for study into the effect of a small change in load on deviation of local frequencies of the network is presented. The network is composed of generators, load buses and branches between the buses. The proposed dynamic model of the network for analyzing the frequency deviation response is implemented within MATLAB-Simulink environment to compare the effect of static loads and induction motor loads. The proposed dynamic network model can be developed in an interconnected network with multi generator buses, load buses and connected branches. This paper also demonstrates the reliable operation of the PID controller for frequency response and the influence of an induction motor through inertia constants on the characteristics of the proposed load frequency controller. The drawbacks of these PID controllers are fixed control gains while the system changes continuously in time. Also in the frequency stability study, the effects of load dynamics and especially induction motor loads on frequency recovery phenomena need to be considered more seriously. 


\section{REFERENCES}

[1] N. Lu, D. P. Chassin, and S. E. Widergren, "Modeling uncertainties in aggregated thermostatically controlled loads using a state queueing model," IEEE Trans. Power Syst., vol. 20, no. 2, pp. 725-733, May 2005.

[2] N. Ruiz, I. Cobelo, and J. Oyarzabal, "A direct load control model for virtual power plant management," IEEE Trans. Power Syst., vol.24, no. 2, pp. 959-966, May 2009

[3] L.T.M.Trang, H. Nouri, "Modeling Dynamic Frequency Control with Power Reserve Limitations," 53rd International Universities Power Engineering Conference (UPEC 2018), 4-7 September 2018, 978-1-5386-29109/18/\$31.00 @2018 IEEE.

[4] H. Omara and F. Bouffard, "A methodology to study the impact of an increasingly nonconventional load mix on primary frequency control," in Proc. IEEE PES General Meeting, Jul. 2009.

[5] X. Quangghu, C. Chen, S. Qu, "The influence of induction motor inerita constant on small-signal stability," Electric Power System Reseach, vol. 72, pp. 192-202, 2005.

[6] B.M Weedy, B.J.Cory, N.Jenkins, J.B. Ekanayake, G.Strbac, Electric power system, 3th ed.UK, Wiley, 2012.

[7] L.L.Grigsby, Power system stability and control, 2nd ed. New York, Taylor \& Francis Group, 2007.

[8] J. Machowski, J. Bialek, and J. Bumby, Power System Dynamics: Stability and Control, 2nd ed. New York: Wiley, 2008.

[9] D.P. Kothari, Modern power System Analysis, 3th ed. Tata McGraw - Hill, 2009.

[10] P. Patnaik, "Load Frequency in a Single Area Power System," Barchelor's thesis, Department of electrical Engineering, National Institude of Technology, Rourkela-769008, May 2013.

[11] A. Usman, B P Divakar, "Simulation Study of Load Frequency Control of Single and Two Area Systems," in Proc. IEEE Global Hamanitarian Technology Conference, 2012.

[12] Q. Shi, H. Cui, F Li, Y Liu, W Ju, Y. Sun, "A Hybrid Dynamic Demand Control Strategy for Power System Frequency Regulation," CSEE Journal of Power and Energy System, vol.3, no.2, June 2017.

[13] A. R. B. Azinan, "Simulation of Dynamic Load Effect on Power System Frequency," Master's thesis of Electrical Engineering with Honors, University Tun Hussein Malaysia, February 2013.

[14] C. Zhao, U. Topcu, and S. H. Low, "Swing dynamics as primal-dual algorithm for optimal load control," in Proc. IEEE Smart Grid Comm, Tainan City, Taiwan, 2012, pp. 570-575.

[15] C.E. Fosha, O. I. Elgerd, "The Megawatt-Frequency Control Problem: A New Approach Via Optimal Control Theory," IEEE Transactions on Power Apparatus and Systems, vol. Pas-89, no.4, April 1970.

[16] C. Zhao, U. Topcu, N. Li, S. Low, "Design and Stability of Load-Side Primary Frequency Control in Power Systems," IEEE Transactions on Automatic Control, vol. 59, no.5, May 2014.

[17] G. Iovan, I. Mircea, "The Load Frequency Control Simulation in the Interconnected Electrical Power System," 9781-4673-1810-5/12/\$31.00, 2012 IEEE.

[18] I. R. Navarro, "Dynamic Load Models for Power Systems," Licentiate thesis, Department of industrila Electrical Engineering and Automation, Lund University, Sweden, 2002.

[19] B. Mohanty, S. Panda, P.K. Hota, "Controller Parameters Tuning of Differential Evolution Algorithm and its Application to Load Frequency control of Multi-Source Power System," Journal homepage: www.elsevier.com/lpcate/ijepes.

\section{BIOGRAPHIES OF AUTHORS}

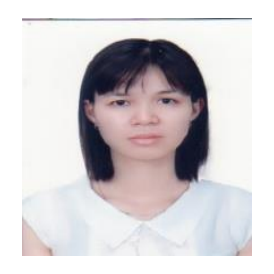

Le Thi Minh Trang graduated bacherlor and master in electrical engineering faculty, Hanoi University of Science and Techinology, Vietnam. Now doing Ph.D in Instrumentations and Control department in Czech Technichcal University in Prague, Czech Republic. Main fields are simulation, analysis stability of power system, Fault Locations and Smart Grids.

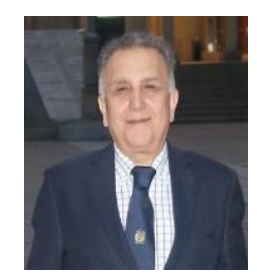

Hassan Nouri Received the B.Sc., M.Sc., and Ph.D. degrees in electrical and electronic engineering from the Universities of Nottingham, Strathclyde and Plymouth respectively. Currently, Reader in Electrical Power and Energy and leader of the Power Systems, Electronics and Control Research Laboratory in the Department of Engineering Design and Mathematics at University of West of England. Areas of expertise are Power Systems Analysis, Power Systems modeling, Power Electronic Applications to Power Systems, Renewable Energy Integration and related issues, DC and AC Micro-Grids, Electric Arc Modeling and Circuit Breakers, Fault Locations, Power Quality and Smart Grids. 